\title{
Objective Structured Clinical Examination (OSCE) as an Assessment Tool for Clinical Skills in Sohag University: Nursing students' perspective
}

\author{
Ghona Abd El-Nasser Ali ${ }^{1}$, Abeer Yahya Mehdi ${ }^{2}$ and Heba Abdel-Kader Ali ${ }^{2}$ \\ ${ }^{1}$ Medical-Surgical Nursing Department, Faculty of Nursing, Sohag University \\ ${ }^{2}$ Medical-Surgical Nursing Department, Faculty of Nursing, Benha University
}

Rec. 6 Jun, 2012 Accpt. 12Aug, 2012

\begin{abstract}
:
The aim of this study was to investigate the students' perception of the OSCE as part of an evaluation of clinical skills in Med-Surgical Nursing students'. A self-administered questionnaire was completed by $1^{\text {st }}$ year Med-Surgical Nursing students immediately after the OSCE exam using Pierre et al., (2004) questionnaire, in addition to 7 questions about the organization of OSCE evaluation. The results of this study indicate that OSCE has been fair assessment tool $(75.9 \%)$ and comprehensive $(72.4 \%)$ and with clear instruction $(50.0 \%)$, minimized the chance of failing (68.9\%), and highlighted areas of student's weakness $(46.6 \%)$. However, some students felt that OSCE was very stressful $(24.1 \%)$, twenty nine $(50.0 \%)$ of student expressed concerns about inadequacy of time. As well, the OSCE provided opportunities to learning, reflected those which were taught (36.2\%), and (48.3\%) reported that the stations were organized and of logical sequence and appropriate. Thirty two $(55.2 \%)$ of the student felt that, the exam score provide true measure clinical skill, (56.9\%) believed that the score was standardized, and the personality and social relations did not affect OSCE scores. Student feedback confirmed their acceptance of OSCE as an evaluation tool for their clinical skills, so as to fairness and unbiased, cover a wide range of knowledge and comprehensive, provide opportunities to leaning. Also the majority of examinees was satisfied with organization and administration of the OSCE; as well prefer using the OSCE exam more in the clinical exams than other assessment. Further studies are required involving larger number of students and staff member to establish the effectiveness of OSCE within nursing education programs, in addition use of Watched Structured Clinical Examination (WSCE) to overcome the limited equipment and manpower.
\end{abstract}

Keywords: Objective Structured Clinical Examination (OSCE), multiple choice questions (MCQ), oral examination, list, true/false, perspective, Watched Structured Clinical Examination (WSCE).

\section{Introduction:}

The Objective Structured Clinical Examination (OSCE) is a form of assessment in, which the student demonstrates clinical skills, and underpinning knowledge, usually in simulated conditions (Fidment, 2012). The OSCE is becoming more prevalent within healthcare education programmes, because it is regarded as a useful method for assessing, skills, and underpinning knowledge required for practice (Merriman and Westcott, 2010). Using the OSCE, as assessment tool for student nurses' clinical competence has been an integral part of the overall assessment strategy since formal nursing assessment began. The objective structured clinical examination (OSCE) has been in use in the assessment of medical students for over 20 years. In the last 10 years, there has been increasing interest in this form of assessment in other health professional disciplines, such as nursing and physiotherapy (Walters and Adams, 2002). OSCE provided an innovative learning experience for students .It offer a valid mean to evaluate students' clinical performance in a holistic manner (Rentschler et al., 2007 and Ahmad et al., 2009; Pierre et al., 2005). added that, OSCE sessions perceived strengths, weaknesses, and challenges in clinical competence, foster self-assessment skills, and provide direction for programme training needs.

Moreover, the important of feedback from nursing students and faculty has been useful in effecting improvements to the process and greater emphasis has been placed on the teaching and evaluation of history taking, communication, and technical

* Corresponding author:

Dr. Ghona Abd El-Nasser Ali

凶ghonaali@yahoo.com 
competencies. It is also sending a clear message to students that the achievement of overall competence is imperative to clinical practice in the current environment (Imani and Tabatabaie, 2005).

During the OSCE examination, students rotate around a circuit of stations on a timed basis (Monaghan et al., 2000). At the ring of a bell, each student enters the station and performs the predefined timed task. Each station assesses a different clinical competency such as history taking, interpretation of clinical data, performing one or more clinical tasks, or solving a problem (Ahmad et al., 2009). The number of OSCE stations is normally from 15 to 20 , and the number of students in each OSCE session is determined by the number of stations. Increased number of the stations enhances the reliability of the assessment (Harden, 1990). by the end of the OSCE stations, all the students will have gone through each station and been marked according to a standardized marking system (El-Nemer and Kandeel, 2009). The advantage of OSCE evaluation over traditional clinical nursing examination is related to the flexibility of the individual components of the stations, which can take the form of small scenarios, simulations, case studies, multiple choice questionnaires or short theoretical questions (Alinier, 2003). Learning in the clinical environment provides the real world context for nursing students to develop the knowledge, skills, attitudes, and values of a registered nurse (Levett-Jones et al., 2007). OSCE also provided a learning opportunity for the nursing students, lecturers, and the institution. First, the students stated that the experience of doing the OSCE gave them a sense of achievement. Lecturers involved in the administration of the OSCE felt that the planning had contributed to a good learning experience for the students (Walters and Adams, 2002).

This kind of research has not been performed before on the students except few researches have evaluated the student's feedback about the OSCE as an assessment tool for their clinical skills in nursing (ElNemer and Kandeel, 2009; Mahmoud and Mostafa, 2011). Another study by (Eldarir et al., 2010). concerning evaluating the effectiveness of OSCE versus traditional clinical assessment, faculty capacity building and students' perspectives. In Sohag the OSCE examination was first introduced into Faculty of Nursing, Sohag University in the January exam 2012 by the Med-Surgical Nursing Department. It was used to assess the first year students' clinical performance first semester following their completion of an introduction to adult nursing course during the 2011-2012 academic years. The main aim of this study was to investigate the students' perception of the OSCE as a part of an evaluation for clinical skills performance in Med-Surgical Nursing candidates.

\section{Subjects and methods:}

\section{Research design and Setting:}

A descriptive study design was uses to fit nature of the study, which was done at Faculty of Nursing, Sohag University, Egypt.

\section{Subjects:}

The study included all first year nursing students $(n=58)$ enrolled in an introduction to adult nursing Course, Faculty of Nursing, Sohag University, Egypt, during the 20112012 academic year (first semester), both males and females.

\section{OSCE feedback questionnaire:}

A. Pierre et al., (2004). OSCE questionnaire was used in this study and it consists of 32 items grouped into 4 sections. For the purpose of this study, only 29 items of Pierre et al., questionnaire were used, with few items were slightly modified to give a clear meaning in Arabic version and become suitable to nursing education assessment formats. The questionnaire used in the current study consists of four main sections:

\section{Section-1:}

this section assesses nursing students' evaluation of the OSCE attributes, and it includes 13 items such as the fairness of the exam, wide range of knowledge and clinical skills covered, time of each station, minimizes chance of failing, and the organization and administration of OSCE. Students' were asked to rate their responses on a 4-point Likert scale ranging: 'no comment', 'disagree', 'neutral', and 'agree'.

\section{Section-2:}

this section looks at nursing students' evaluation of the quality of OSCE performance and it comprises 8 items 
involving students' awareness of the nature of the exam, tasks of the exam, structure of the exam and the adequacy of the time at each station.

\section{Section-3:}

this section investigates nursing students' evaluation of the OSCE scoring and objectivity, and it incorporates 4 items addressing the standardization of the OSCE score, and its usefulness and objectivity. For second and third sections, students' were asked to rate their responses on a 3-point Likert scale ranging: 'not at all', 'neutral' and 'to a great extent'.

\section{Section-4:}

this section assesses nursing students' opinion about the usefulness of the OSCE as an assessment instrument compared to other forms, which they had experienced (multiple-choice questions, definition, OSCE, true or false, list and oral exam) and it comprises 4 items. A 3- Likert scale was used to assess each according to the evaluative labels. Alpha Crombach test was used to test the reliability of the questionnaire. Alpha score for the 29 items questionnaire (section $1,2,3, \& 4$ ) is 0.77 .

\section{B. OSCE organization Section:}

this section of the questionnaire investigates nursing students' evaluation of the OSCE organization. Designed by the investigators and included 7 items such as: (the announcement of the place and time table of examination, revision and cooperation of staff to answer any question about the examination, the quality of OSCE labs, and the availability and quality of equipment and simulators. A 5-point Likert scale, with responses ranging from poor to Excellent was used. Also the internal consistency as measured by Crombach alpha to test the reliability of the questionnaire. Alpha score for these items of the questionnaire was 0.72 which indicates that the tool is reliable. The overall score of OSCS items was calculated for students by summing the scores of the sections except formats section. The total score system was arranged from 32 to 123 points.

\section{Methods:}

\section{Ethical Consideration:}

The researcher to obtain an approval to conduct the research study was receiving official permissions from the Faculty of Nursing Ethics Committee Sohag University, Egypt, after full explanation of the aim of the study and its reflection on developing the clinical teaching methods at the faculty.

\section{Translation of the OSCE Questionnaire:}

The questionnaire was translation into Arabic version by the researchers. To ensure the validity of tool translation, back-translation technique was used by an expert in English language from Faculty of Education, English Department. In addition, the section of the OSCE organization tool was translation, and revised by the same expert for its English language. The content validity of the tool was checked and revised by five expert professors in the same field and the required corrections and modifications were done accordingly. Finally, the questionnaire was pre-tested on a group of $10 \%$ of the student sample and modification were done for any ambiguity or vagueness

\section{Preparing of OSCE:}

All department staff prepared the OSCE stations, and it consisted of a series of 6 stations included the following: Four stations were photo's stations to recognize the different photos related to the clinical course. One station was instrument's station to recognize the name and function of the Medical-Surgical nursing instrument. In the last station the students ' were asked to carry out one procedure according to their selection by using simple random sampling method such as: hand washing, bed making, administration oral medication, vital signs, physical examination, positioning, moving and turning position, weight measurement, and specimen collection after preparing the suitable equipment using simulated patients. To overcome the limited number of a simulator in the skill labs, standardized patients were used in the OSCE.

\section{Training of Staff and students:}

To accomplish the aim of the study, all the staff received detailed training on OSCE before the actual exam, allocated one staff for preparing the environment, and coordinated the OSCE. Also, two faculty 
staff from the critical care and two from geriatric nursing department were trained to perform a role playing for a specific procedure, such as vital signs and oral medication. As well, the students one week prior to OSCE exam training in the skill labs in addition to received an orientation about the nature of the OSCE at each station, the process of the examination, skill under review, marking criteria, opportunities to view skill station and given as written information in the handbook, also students were encouraged to ask questions and discuss issues around the OSCE.

\section{Administration of the OSCE:}

The OSCE answer booklet was prepared prior including a cover sheet, the instruction sheet, and a separate sheet for each station. Observation check lists were prepared for clinical procedures. A standardized technique of marking was used and student performance was assessed by Rubric test for all OSCE answer booklet. Before starting the OSCE, the staff coordinator read the instruction to students, and then all students in the skill labs went through the same stations by moving around a series of stations. They moved each 5 minutes from one station to another to cover all stations except in photo station they moved after 3 minutes when hearing the ring of a bell as a time keeper in skill lab and indicating the end of that station. Each student taken about 22 minutes to complete the all stations and one minute was given between stations to facilitate movement and to prevent push between stations and allowed them for reading of the instructions, in addition to rest station where students have 5-minute break.

\section{Collecting Students' Feedback:}

Immediately after the OSCE and in a place out of test, all students were received full explanation of the aim of the study. The questionnaires were distributed to all students' to answer with sufficient comfort to attain students' perceptions about OSCE as an assessment tool for their clinical skills in an introduction to adult nursing course. Each student was on a voluntary basis, and all students were assured that the study would be conducted anonymously to protect their confidentiality and information obtained will be confidential and used only for the purpose of the study. Students' were given the opportunity to review their individual performances, than did not share study would not be affected in anyway.

\section{Statistical design:}

Statistical analysis was done by using the Statistical Package for Social Science (SPSS version 16). The obtained data were coded, analyzed and tabulated. Basic descriptive statistical analysis of the Likert items was performed in the forum of frequencies, means and standard deviations. Qualitative analysis was done through a form of content analysis by identifying themes in students' responses and regrouping the responses into similar categories.

\section{Results:}

Table (1) represents nursing students' perception of OSCE attributes. The results of the questionnaire revealed that the majority of students $75.9 \%$ perceived OSCE as a fair, covered a wide range of knowledge and comprehensive (72.4\%), and well administered (79.3\%). Twenty nine $50.0 \%$ of the students' agreed that the stations need to more time to complete the station, and $86.2 \%$ felt the OSCE stations were arranged in an organized and well-sequenced order. Although nearly half of students believed that, the exam was an intimidating method of assessment, more than half $56.9 \%$ of students felt that, QSCE was less stressful than other type of test they have been through before. Forty (68.9\%) of students perceived that, the nature of exam process minimized the chance of failing, while more than two thirds of the students $(67.2 \%)$ thought that their performance on OSCE would allowed to compensate in some areas of course and improve their overall final grade for the course, especially if they did not perform as well on other course examination that used other assessment methods. An overwhelming proportion of the examinees $70.7 \%$ considered that, the OSCE cover a wide range of clinical skills and competencies. A sizable proportion $(46.6 \%)$ of the examinees agreed that, the OSCE assessment process helped to identify areas of weakness and gaps in their competencies, so that remedial work could be made, and $55.2 \%$ of students were fully aware of level of information needed to accomplish the examination tasks. 
In case of assessment of the quality of OSCE performance (Table 2). The majority of student $70.7 \%$ said they were aware of nature of the OSCE prior to the examination, twenty one (36.2\%) of the student stated that the task reflect which were taught, forty four (75.9\%) of the students' felt that the task they asked to perform in the OSCE were fair. Regarding to the logical sequence and the appropriateness of the stations, nearly half of students $48.3 \%$ agreed about the logical sequence of the station and $84.5 \%$ felt that the exam provides opportunity to learning experience and that the content reflected real life situation. Also $69.0 \%$ of the student felt that, each station was authentic. As well nearly half $(44.8 \%)$ of student felt the time allocated for each station was adequate, and the instruction providing were clear and lacked ambiguous this was reported by 50.0 $\%$.

Table (3) illustrates nursing students' perception of validity and reliability of OSCE scoring system. Just over half (56.9\%) of student believed that OSCE was standardized and $55.2 \%$ of the students were to great extent agreed that their performance on the examination was a true reflection of their clinical skills. Also $58.6 \%$ of students thought that, the OSCE was a practical and useful experience for them, as well more than two thirds (72.4\%) of the students responded to question about bias due to personality and social relations, were not affected on OSCE scores.

Table (4) describes the nursing student's perceptions about the organization of OSCE. It was ranked as poor to excellent .More than half of the student's considered the announcement of the date and the places of the examination in the areas available for all students and early was excellent (55.2\%; $51.7 \%$ respectively). It was clear from the results that $(44.8 \%)$ of the student considered the revision done before exam was good and they were more prepared and ready for OSCE, while nearly half of the student's considered the orientation and gave general idea about the nature of exam before beginning and cooperation of the staff was excellent $(41.4 \% ; 44.8 \%$ respectively). The study also showed that, about one third of student's $32.8 \%$ considered the quality of the examination places was poor, while $43.1 \%$ got a very good score to the quality and presence of enough equipment and simulators for OSCE test.

Table (5) presents mean scores and standard deviation of nursing students' perceptions regarding the OSCE exam. It was found that, the mean scores of student opinion according to the OSCE attributes and the quality of performance were $(19.3 \pm 4.9$; $12.2 \pm 3.0$ respectively), while the validity and reliability, and organization of exam were $(6.0 \pm 1.7 ; 24.3 \pm 6.0)$ with the total mean score was $(61.7 \pm 9.3)$.

Students were also asked to rate various assessment instruments in terms of difficulty, fairness, degree of learning, and their preferences on the frequency with which the instruments should be used for assessing clinical skills. The results are summarized in Table (6). Generally, our study revealed that, the frequency of student who believed that, definition and list form assessment were easy by $(60.3 \% ; 51.7 \%$ respectively) than those observed for MCQs, OSCE, truelfalse, while $62.1 \%$ rated oral exam as the most difficult form of assessment. On the other hand, just over half $(58.6 \%)$ of the students' considered the list format is the fairest assessment format. Furthermore, definition $44.8 \%$ and OSCE rating $43.1 \%$ were considering the most learning experience compared to the other assessment formats. Forty one (70.7\%) of the student reported that, OSCE were suitable tool for evaluation of the practice clinical skills and should be used more as compared to other formats.

\section{Discussion:}

The objective structured clinical examination (OSCE) is a valuable tool for assessing clinical skills and competences that are not easily evaluated by other testing methods. The findings of the study about the first question on students' view toward OSCE attributes revealed that, the OSCE has been considered as an acceptable method for assessment for clinical skills in nursing students'. This was demonstrated by the favorable responses concerning transparency and fairness of the examination process and the authenticity of the task per station and covering a board area of knowledge, allowed them to compensate in some areas and gave a chance for the large number of students to 
minimize their failing. This results are consistent with (Pierre et al., 2004 and AL Omari and Shawagfa, 2010). who said that, the majority of students in our cohort agreed about, the OSCE exam characteristic as comprehensiveness by $90 \%$, transparency $87 \%$, fairness $70 \%$ and authenticity of the required task $58-78 \%$. Similar results by (Eldarir et al., 2011 and Rupalisalvi, 2011). On other hand, present study revealed that, more than half $56.9 \%$ of students felt that, the OSCE exam was less stressful than other assessment formats, while a considerable percentage of students' believed that, the exam was intimidating. These results were in agreement with (Furlong et al., 2005 and Selim et al., 2012). who reported that, the majority of students' felt the OSCE was less stressful than other exam and intimidating. Similar results by (Ryan et al., 2007).

According to the view of the students toward the quality of OSCE performance, the majority provided positive view about the OSCE quality performance in term of the clarity of the instruction of the exam, the reflection of the task taught, provided opportunities to learn, and the sequence of the OSCE station. These findings are convenience with (El-Nemer and Kandeel, 2009). who said that, the majority of students reported that, they were fully aware of the nature of the exam, that OSCE provided them with more learning opportunities, and also reflected those which were taught. (Pierre et al., 2004). added that, OSCE was seen as a positive and useful practical experience by most students'. Our study noticed that, $17.2 \%$ of the students complained from the insufficient time allowed at each station for the expected tasks. This result was consistent with (Monaghan et al., 2000 and Zartman et al., 2002). who said that, the insufficient time at OSCE station was one of students' complaints in some of the studies, which investigated students' perspective of OSCE.

As regards to the view of the students' toward the validity and reliability of OSCE scoring system. The present study revealed that, the questionnaire study indicated that, positive view about the OSCE scoring system was standardized; exam score provide true measure of essential clinical skills. These results is in agreement with (El-
Nemer and Kandeel, 2009). they found that, more than half of the students believed that, the score were standardized and reflected actual measure of essential clinical skills. The study was somewhat similar to the view of student at (Pierre et al., 2004). As regards to the effect of personality and social relations on OSCE scores, it was found that, the student responses to the question about bias due to gender, personality or ethnicity wear not interpretable. (Rushforth, 2006 and Dastjerdie et al., 2010). added that, OSCE were generally more objective than most other assessments of practice and the wide range of assessors involved reduced the risk of examiner bias.

According to the view of the students toward the organization of the OSCE exam. More than half of the students considered the early announcement date and the place in the areas available for all students was excellent, and $44.8 \%$ of the student considered the revision done before exam as good act to be more prepared and ready for OSCE. Also, nearly half of the students considered the orientation to give general idea about the exam before beginning and cooperation of the staff was excellent. One third of the student's $32.8 \%$ considered the quality of the examination places was poor, while $43.1 \%$ gave a very good score to the presence of enough equipment and simulators for OSCE test. This results were convenience with (Mahmoud and Mostafa, 2011). who reported that, more than one third of the students considered the announcement of the date and the place of the examination was very good, also more than two thirds of the students were agreed that, the equipments and manikins for OSCE were enough. In the study by (Hosseini et al., 2011). he found that, the view of most of students in OSCE test has been good in terms of equipment and facilities with relative frequency of 59.2 percent. On the other hand, (Turner and Dankoski, 2008; Pharm and Sturp, 2010). found that, a major obstacle in the wide implementation of OSCEs was their high cost. However, it could be set up with reasonable cost and limited resources even in smaller institutions.

According to point of view of students on various assessment formats to which they had been exposed. The study found that, the 
higher proportion of students perceived the OSCE as fair and it must be used most in the clinical exam than other assessment. These results are in agreement with (Pierre et al., 2004; El-Nemer and Kandeel, 2009). In the study by (Fidment, 2012). he reported that, the students' value the OSCE as a worthwhile assessment.

The limitations of this study summarized as, only small numbers of OSCE stations were used due to resource and places limitations, in addition to shortage in the staff member.

\section{Conclusions:}

Although the implementation of OSCE in the Medical-Surgical Nursing Department, faculty of Nursing, Sohag University for $1^{\text {st }}$ year students has been challenging due to lack of facilities, staff members and the students also did not pass on this types of tests before. The OSCE exam was an acceptable method for evaluation as view by participating students' and their overall acceptance of the instrument. This appears in student feedback which confirmed their acceptance of OSCE, so as to fairness, unbiased, easiest, cover a wide range of knowledge and comprehensive tool for assessment. The students' noted that, the exam was well-structure and sequence, provide opportunities to leaning experience and reflected real life situation. Also the majority of examinees was satisfied with conduct, organization and administration of the OSCE; as well prefer using the OSCE exam more in the clinical exams than other assessment tools.

\section{Recommendations for future practice:}

- Based on findings of the current study, it is recommended that, OSCE must be used as an integral part of the overall assessment strategy at the under graduate educational programs.

- OSCE should be used as a method of evaluation in conjunction with other classical clinical examinations method.

- OSCEs can be used most effectively in nurse undergraduate curricula to assess safe practice in terms of performance of psychomotor skills, as well as the declarative and schematic knowledge associated with their application.

- Use of Watched Structured Clinical Examination (WSCE) to overcome the limited equipment and manpower in arrange, supervise, conduct and score and, more importantly, it is less stressful to the students.

- Further studies are required involving larger number of students and staff member to establish the effectiveness of OSCE within nursing education programs.

\section{Acknowledgements:}

We wish to thank the English language department, Faculty of Education for questionnaires translation and all panel examiners who participated in succession the first learning experience of OSCE in faculty of Nursing, Sohag University both in preparing and executing the OSCE. We also express our deepest gratitude to all first year nursing students for their valuable feedback.

\begin{tabular}{|l|c|c|c|c|}
\hline \multicolumn{1}{|c|}{ Srvey Item } & \multicolumn{3}{c|}{ Degree of Response } \\
\cline { 2 - 5 } & $\begin{array}{c}\text { Agree } \\
\mathbf{N}(\boldsymbol{\%})\end{array}$ & $\begin{array}{c}\text { Neutral } \\
\mathbf{N}(\mathbf{\%})\end{array}$ & $\begin{array}{c}\text { Disagree } \\
\mathbf{N}(\mathbf{\%})\end{array}$ & $\begin{array}{c}\text { No comment } \\
\mathbf{N}(\mathbf{\%})\end{array}$ \\
\hline Exam was fair & $44(75.9)$ & $6(10.3)$ & $6(10.3)$ & $2(3.4)$ \\
\hline Wide knowledge area covered & $42(72.4)$ & $3(5.2)$ & $13(22.4)$ & $0(0.0)$ \\
\hline Needed more time at station & $29(50.0)$ & $6(10.3)$ & $23(39.7)$ & $0(0.0)$ \\
\hline Exams well administer & $46(79.3)$ & $2(3.4)$ & $9(15.5)$ & $1(1.7)$ \\
\hline Exams very stressful & $14(24.1)$ & $7(12.1)$ & $33(56.9)$ & $4(6.9)$ \\
\hline Exams well structured \& sequenced & $50(86.2)$ & $3(5.2)$ & $5(8.6)$ & $0(0.0)$ \\
\hline Exam minimized chance of failing & $40(68.9)$ & $3(5.2)$ & $12(20.7)$ & $3(5.2)$ \\
\hline OSCE less stressful than other exam & $41(70.7)$ & $6(10.3)$ & $10(17.2)$ & $1(1.7)$ \\
\hline Allowed student to compensate in some areas & $39(67.2)$ & $1(1.7)$ & $16(27.6)$ & $2(3.4)$ \\
\hline Highlighted areas of weaknesses & $27(46.6)$ & $4(6.9)$ & $26(44.8)$ & $1(1.7)$ \\
\hline Exam intimidating & $25(43.1)$ & $24(41.4)$ & $7(12.1)$ & $2(3.5)$ \\
\hline Student aware of level of information needed & $32(55.2)$ & $6(10.3)$ & $19(32.8)$ & $1(1.7)$ \\
\hline Wide range of clinical skills covered & $41(70.7)$ & $7(12.1)$ & $10(17.2)$ & $0(0.0)$ \\
\hline
\end{tabular}

Table (1). Nursing Students' evaluation of the OSCE Attributes 


\begin{tabular}{|l|c|c|c|}
\hline \multicolumn{1}{|c|}{ Survey Item } & \multicolumn{3}{c|}{ Degree of Response } \\
\cline { 2 - 4 } & $\begin{array}{c}\text { To greet extent } \\
\mathbf{N}(\mathbf{\%})\end{array}$ & $\begin{array}{c}\text { Neutral } \\
\mathbf{N}(\mathbf{\%})\end{array}$ & $\begin{array}{c}\text { Not at all } \\
\mathbf{N}(\boldsymbol{\%})\end{array}$ \\
\hline Fully aware of the nature of the exam & $41(70.7)$ & $13(22.4)$ & $4(6.9)$ \\
\hline Tasks reflected those taught & $21(36.2)$ & $19(32.7)$ & $18(31.0)$ \\
\hline Time at each station was adequate & $26(44.8)$ & $22(37.9)$ & $10(17.2)$ \\
\hline Setting and context at each station felt authentic & $40(69.0)$ & $15(25.9)$ & $3(5.2)$ \\
\hline Instructions were clear and unambiguous & $29(50.0)$ & $22(37.9)$ & $7(12.1)$ \\
\hline Tasks asked to perform were fair & $44(75.9)$ & $10(17.2)$ & $4(6.9)$ \\
\hline Sequence of stations logical and appropriate & $28(48.3)$ & $20(34.5)$ & $10(17.2)$ \\
\hline Exam provided opportunities to learn & $49(84.5)$ & $6(10.3)$ & $3(5.2)$ \\
\hline
\end{tabular}

Table (2). Nursing Students' assessment of the quality of OSCE performance

\begin{tabular}{|l|c|c|c|}
\hline \multicolumn{1}{|c|}{ Survey Item } & \multicolumn{3}{c|}{ Degree of Response } \\
\cline { 2 - 4 } & $\begin{array}{c}\text { To greet extent } \\
\text { N }(\%)\end{array}$ & $\begin{array}{c}\text { Neutral } \\
\text { N }(\%)\end{array}$ & $\begin{array}{c}\text { Not at all } \\
\text { N }(\%)\end{array}$ \\
\hline OSCE scores provide true measure of essential clinical skills & $32(55.2)$ & $20(34.5)$ & $6(10.3)$ \\
\hline OSCE scores are Standardized & $33(56.9)$ & $19(32.8)$ & $6(10.3)$ \\
\hline OSCE practical and useful experience & $34(58.6)$ & $18(31.0)$ & $6(10.3)$ \\
\hline Personality and social relations will not affect OSCE scors & $42(72.4)$ & $6(10.3)$ & $10(17.2)$ \\
\hline
\end{tabular}

Table (3). Nursing Students' evaluation of an OSCE validity and reliability

\begin{tabular}{|l|l|l|l|l|l|}
\hline \multicolumn{2}{|c|}{ Survey Item } & \multicolumn{5}{|c|}{ Degree of Response } \\
\cline { 2 - 5 } & $\begin{array}{l}\text { Poor } \\
\mathbf{N}(\%)\end{array}$ & $\begin{array}{l}\text { Good } \\
\mathbf{N}(\%)\end{array}$ & $\begin{array}{l}\text { Very go } \\
\mathbf{N}(\%)\end{array}$ & $\begin{array}{l}\text { Excellent } \\
\mathbf{N}(\%)\end{array}$ & $\begin{array}{l}\text { Total } \\
\mathbf{N}(\%)\end{array}$ \\
\hline $\begin{array}{l}\text { 1-The announcement about the place of OSCE examination: } \\
\text { 2-The time tables of OSCE examination were available and }\end{array}$ & $3(5.2)$ & $18(31.0)$ & $5(8.6)$ & $32(55.2)$ & $58(100.0)$ \\
\hline $\begin{array}{l}\text { known to student early: } \\
\text { 3-The revision done before the examination about } \\
\text { the different types of clinical procedure: }\end{array}$ & $4(6.9)$ & $16(27.6)$ & $8(13.8)$ & $30(51.7)$ & $58(100.0)$ \\
\hline 4-Gave general idea about the OSCE before exam process: & $17(29.3)$ & $26(44.8)$ & $3(5.2)$ & $12(20.7)$ & $58(100.0)$ \\
\hline $\begin{array}{l}\text { 5-The cooperation of the staff to answer your questions related to } \\
\text { organization of the examination: }\end{array}$ & $12(20.7)$ & $15(25.9)$ & $5(8.6)$ & $26(44.8)$ & $58(100.0)$ \\
\hline $\begin{array}{l}\text { 6-The quality of the OSCE labs from set up and cleanliness, } \\
\text { suitable, lightening, quietness and ventilation: }\end{array}$ & $19(32.8)$ & $16(27.6)$ & $9(15.5)$ & $14(24.1)$ & $58(100.0)$ \\
\hline 7-The availability of needed equipments, simulators in good quality: & $14(24.1)$ & $15(25.9)$ & $25(43.1)$ & $4(6.9)$ & $58(100.0)$ \\
\hline
\end{tabular}

Table (4). Frequency distribution of nursing students' perceptions regarding to OSCE organization

\begin{tabular}{|l|c|c|c|}
\hline \multicolumn{1}{|c|}{ Survey Items } & $\begin{array}{c}\text { Students' } \\
\text { Response Mean } \\
\pm \text { SD }\end{array}$ & Median & Range \\
\hline Section of OSCE attributes & $19.3 \pm 4.9$ & 18.0 & $(13-33)$ \\
\hline Section of OSCE quality & $12.2 \pm 3.0$ & 11.5 & $(8-21)$ \\
\hline $\begin{array}{l}\text { Section of OSCE validity and } \\
\text { reliability }\end{array}$ & $6.0 \pm 1.7$ & 6.0 & $(4-12)$ \\
\hline Section of OSCE Organization & $24.3 \pm 6.0$ & 25.0 & $(9-35)$ \\
\hline Total mean scores & $61.7 \pm 9.3$ & 61.0 & $(34-85)$ \\
\hline
\end{tabular}

Table (5). Mean score and standard deviation to students' perspective $(n=58)$

OSCE $=$ objective structured clinical examination 


\begin{tabular}{|c|c|c|c|}
\hline 1-Which of the following methods is easiest? & $\begin{array}{l}\text { Difficult } \\
\mathbf{N}(\%)\end{array}$ & $\begin{array}{l}\text { Undecided } \\
\mathbf{N}(\%)\end{array}$ & $\begin{array}{l}\text { Easy } \\
\mathbf{N}(\%)\end{array}$ \\
\hline MCQ & $33(56.9)$ & $16(27.6)$ & $9(15.5)$ \\
\hline Definition & $10(17.2)$ & $13(22.4)$ & $35(60.3)$ \\
\hline OSCE & $20(34.5)$ & $23(39.7)$ & $15(25.9)$ \\
\hline True or False & $20(34.5)$ & $23(39.7)$ & $15(25.9)$ \\
\hline List & $13(22.4)$ & $15(25.9)$ & $30(51.7)$ \\
\hline Oral exam & $36(62.1)$ & $21(36.2)$ & $1(1.7)$ \\
\hline 2- Which of the following methods is fairest? & $\begin{array}{l}\text { Unfair } \\
\text { N(\%) }\end{array}$ & $\begin{array}{l}\text { Undecided } \\
\mathbf{N}(\%)\end{array}$ & $\begin{array}{l}\text { Fair } \\
\mathbf{N}(\%)\end{array}$ \\
\hline MCQ & $15(25.9)$ & $12(20.7)$ & $31(53.4)$ \\
\hline Definition & $12(20.7)$ & $22(37.9)$ & $24(41.4)$ \\
\hline OSCE & $11(19.0)$ & $14(24.1)$ & $33(56.9)$ \\
\hline True or False & $17(29.3)$ & $20(34.5)$ & $21(36.2)$ \\
\hline List & $10(17.2)$ & $14(24.1)$ & $34(58.6)$ \\
\hline Oral exam & $26(44.8)$ & $28(48.3)$ & $4(6.9)$ \\
\hline $\begin{array}{l}\text { 3-From which of the following methods do } \\
\text { you learn most? }\end{array}$ & $\begin{array}{l}\text { Learn very } \\
\text { little } \mathrm{N}(\%)\end{array}$ & $\begin{array}{l}\text { Undecided } \\
\mathrm{N}(\%)\end{array}$ & $\begin{array}{l}\text { Learn a lot } \\
\mathbf{N}(\%)\end{array}$ \\
\hline MCQ & $17(29.3)$ & $25(43.1)$ & $16(27.6)$ \\
\hline Definition & $12(20.7)$ & $20(34.5)$ & $26(44.8)$ \\
\hline OSCE & $5(8.6)$ & $28(48.3)$ & $25(43.1)$ \\
\hline True or False & $23(39.7)$ & $22(37.9)$ & $13(22.4)$ \\
\hline List & $23(39.7)$ & $19(32.8)$ & $16(27.6)$ \\
\hline Oral exam & $19(32.8)$ & $37(63.8)$ & $2(3.4)$ \\
\hline $\begin{array}{l}\text { 4-Which of the following methods should be } \\
\text { used more often in the clinical progrmme? }\end{array}$ & $\begin{array}{l}\text { Used much less } \\
\mathbf{N}(\%)\end{array}$ & $\begin{array}{l}\text { Undecided } \\
\mathbf{N}(\%)\end{array}$ & $\begin{array}{l}\text { Used much more } \\
\quad \mathbf{N}(\%)\end{array}$ \\
\hline MCQ & $31(53.4)$ & $16(27.6)$ & 11(19.0) \\
\hline Definition & $31(53.4)$ & $20(34.5)$ & $7(12.1)$ \\
\hline OSCE & $9(15.5)$ & $8(13.8)$ & $41(70.7)$ \\
\hline True or False & $35(60.3)$ & $14(24.1)$ & $9(15.5)$ \\
\hline List & $24(41.4)$ & $23(39.7)$ & $11(19.0)$ \\
\hline Oral exam & $37(63.8)$ & 19(32.8) & $2(3.4)$ \\
\hline Total mean scores & \multicolumn{3}{|c|}{$47.2 \pm 7.4$} \\
\hline
\end{tabular}

Table 6. Nursing students' rating of OSCE in relation to other assessment methods used in nursing education

$\mathrm{MCQ}=$ multiple choice question

OSCE $=$ Objective Structured Clinical Examination

References:

Ahmad, C., Ahmad, N., Abu Baker, R. (2009). Assessing Nursing Clinical Skills Performance Using Objective Structured Clinical Examination (OSCE) for Open Distance Learning Students in Open University Malaysia. International Conference on Information; Kuala Lumpur, 195203.

Alinier, G. (2003). Nursing students' and lecturers' perspectives of objective structured clinical examination incorporating simulation. Nurse Education Today, 23 (6): 419-26.
AL Omari, A. and Shawagfa, Z. (2010). New experience with objective structured clinical examination in Jordan. Rawal Med J 35(1): 1-5.

Dastjerdie, E .V., Saboury, A., Mahdian, M. et al., (2010). Assessment of Iranian lecturers attitude and perspectives toward objective structured clinical examination (OSCE).Research Journal of Biological Sciences 5 (3): 241-45.

Eldarir, S.A., El Sebaae, H.A., El Feky, H.A. et al., (2010). An Introduction of OSCE versus Traditional Method in Nursing Education: Faculty Capacity 
Building \& Students' Perspectives, Journal of American Science;6 (12): 1002-14.

El-Nemer, A. and Kandeel, N. (2009). Using OSCE as an Assessment Tool for Clinical Skills: Nursing Students' Feedback. Australian Journal of Basic and Applied Sciences, 3(3): 2465-72.

Fidment, S. (2012). The Objective Structured Clinical Exam (OSCE): A Qualitative Study exploring the Healthcare Student's Experience. Student Engagement and Experience Journal, 1 (1): 1-11.

Furlong, E., Fox, P., Lavin, M., and Collins, R. (2005). Oncology nursing students' views of a modified OSCE. European Journal of Oncology Nursing, 9: 351-59.

Harden, R. (1990). Twelve tips for organizing an objective structured clinical examination (OSCE). Medical Teacher, 12: 259-64.

Hosseini, S.A., Fatehi, N., Eslamian, J. et al., (2011). Reviewing the nursing students' views toward OSCE test. IJNMR; 16 (4): 318-20.

Imani, and Tabatabaie, (2005). Is OSCE successful in pediatrics? Journal of Medical Education; 6 (2): 153-58.

Levett-Jones, T. and Lathlean, J. (2007). Belongingness: A prerequisite for nursing Students' clinical learning, Nurse Education in Practice, 8: 10311.

Mahmoud, A.G., Mostafa, M.F. (2011). The Egyptian Nursing Student's Perceptive view about an Objective Structured Clinical Examination (OSCE). Journal of American Science; 7 (4): 730-38.

Merriman, C. and Westcott, L. (2010). Succeed in OSCEs and Practical Exams: An Essential Guide for Nurses, $1^{\text {st }}$ ed. Milton Keynes, Open University Press.

Monaghan, M.P., Turner, R., Vanderbus, and Grady, A. (2000). Traditional student, non traditional student, and pharmacy practioner attitudes towards the use of standardized patients in the assessment of clinical skills. American Journal of Pharmaceutical Education, 64: 2732.

Pierre, R.B., Wierenga, A, and Barton, M. et al., (2004). Student evaluation of an OSCE in pediatric at the University of the West Indies, Jamaica, BMC Medical Education, 4 (22): 1-7.

Pierre, R.B., Wierenga, A. and Barton, M. et al., (2005). Student self-assessment in a pediatric objective structured clinical examination. West Indian med. J. 54 (2): 144-8

Pharm, D. and Sturpe, D.A. (2010). Objective structured clinical examinations in doctor of pharmacy program in the United States. American Journal of Pharmaceutical Education. 74 (8): 1-6.

Rentschler, D.J., Eaton, J., Cappiello, et al., (2007). Evaluation of undergraduates' students using objective structured clinical evaluation. Research Briefs, 46 (3): 135-39.

Rupalisalvi, M. (2011). Use of OSCE to assess ANC examination. Sinhad eJournal of Nursing, 1 (2): 1-3.

Ryan, S., Stevenson, K., Hassell, A.B. (2007). Assessment of clinical nurse specialists in rheumatology using an OSCE. Musculoskelet. Care 5: 11929.

Selim, A.A., Ramadan, F.H., El-Gueneidy, M.M. et al., (2012). Using Objective Structured Clinical Examination (OSCE) in undergraduate psychiatric nursing education: is it reliable and valid? Nurse Educ Today; 32 (3): 283-8.

Turner, J.L. and Danksoki, M.E. (2008). Objective structured clinical exams: a critical review, Family Medicine. September, 574-78.

Walters, J. and Adams, J. (2002): A child health nursing Objective Structured Clinical Examination (OSCE). Nurse Education in Practice; 2: 224-29.

Zartman, R.A. McWhorter, S. Seale, et al., (2002). Using OSCE-based evaluation: curricular impact over time. Journal of Dental Education, 66 (12): 1323-30. 
وجهة نظر طلاب كلية التمريض جامعة سوهاج عن التقييم الإكلينيكي موضعي البناء كأداة تقيم المهارات العملية الملية

$$
\begin{aligned}
& \text { غُني عبد الناصر علي'، عبير يحيى مهدي'، هبة عبد القادر علي' } \\
& \text { 'قسم التمريض الباطني و الجر احي (تمريض بالغين) كلية التمريض- جامعة سو هاج }
\end{aligned}
$$

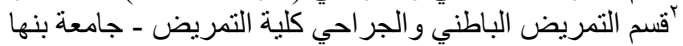

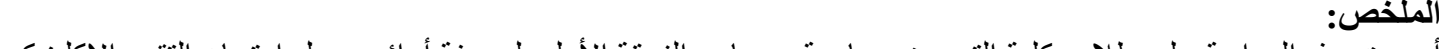
أجريت هذه الدراسة علي طلاب كلية التمريض جامعة سو هاج ـالفرقة الأولي لمعرفة أر ائهم حول امتحان التقييم الإكلينيكي

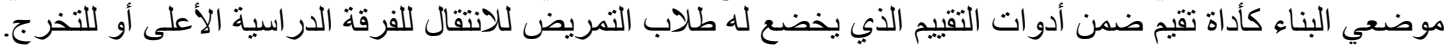

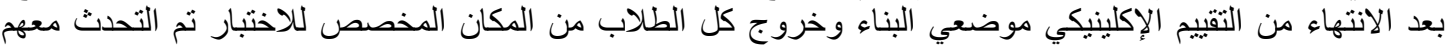

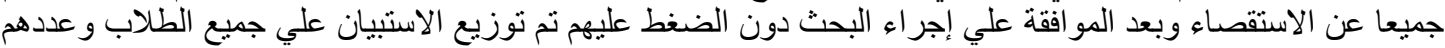



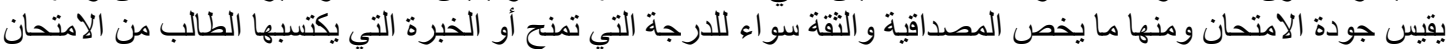





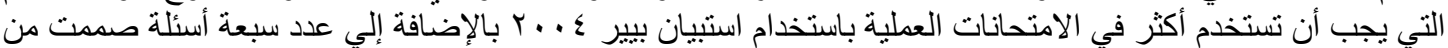

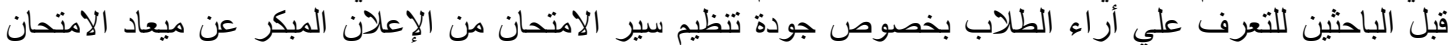

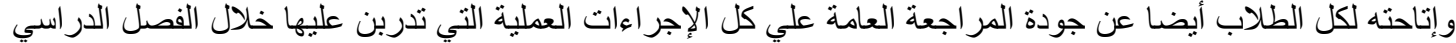



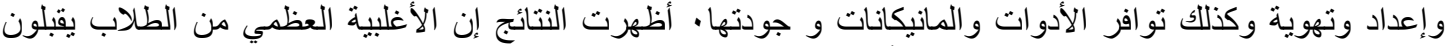



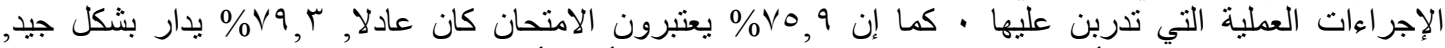





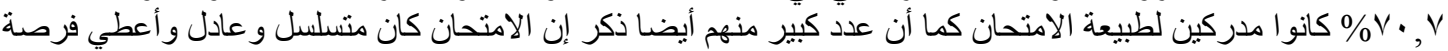



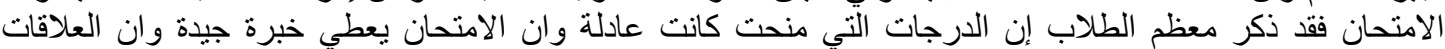

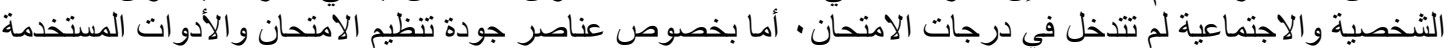

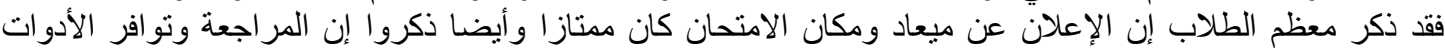

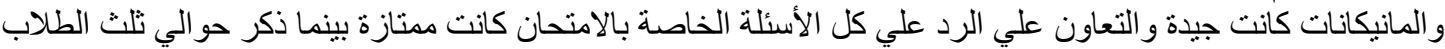



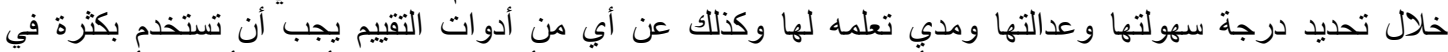

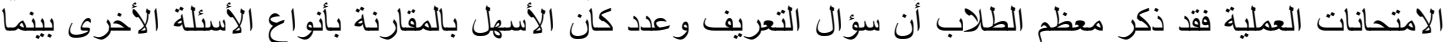

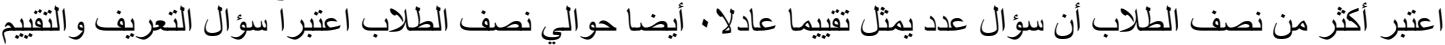

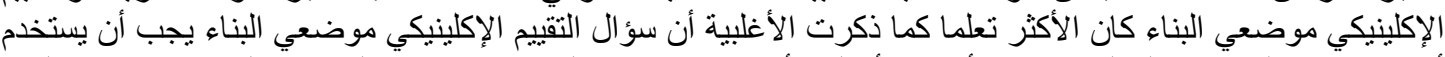





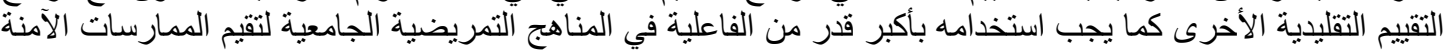

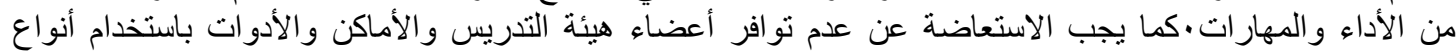

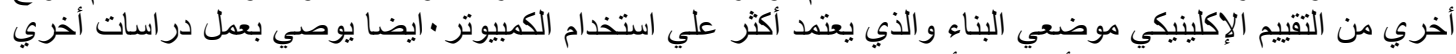

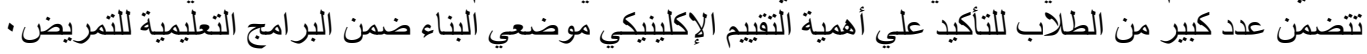

